\title{
Developmental and light regulation of eas, the structural gene for the rodlet protein of Neurospora
}

\author{
Frank-Roman Lauter, Vincenzo E.A. Russo, ${ }^{1}$ and Charles Yanofsky ${ }^{2}$ \\ Department of Biological Sciences, Stanford University, Stanford, California 94305 USA; ${ }^{1}$ Max-Planck-Institut für \\ molekulare Genetik, Abteilung Trautner, D1000 Berlin-Dahlem, Germany
}

\begin{abstract}
The surface of many fungal spores is covered by a hydrophobic sheath termed the rodlet layer. We have determined that the rodlet protein of Neurospora crassa is encoded by a cloned gene designated bli- 7 , and that bli-7 is identical to the known gene eas (easily wettable). Using eas DNA as a probe we show that eas mRNA is abundant in illuminated mycelia and conidiophores but is not detectable or is barely detectable in dark-grown mycelia, mature macroconidia, microconidia, and ascospores. Mutations in the genes acon-2, acon-3, and $f l$ block early conidiophore development; of these, only fl prevents normal eas transcription. The EAS protein is homologous to the rodlet protein (RodA) of Aspergillus nidulans, and the hydrophobins of Schizophyllum commune. eas is the first cloned conidiation (con) gene of $N$. crassa that is associated with a phenotypic alteration.
\end{abstract}

[Key Words: eas gene; rodlet protein; conidia; Neurospora crassa; blue light; regulation]

Received August 3, 1992; revised version accepted September 9, 1992.

During asexual differentiation in the fungus Neurospora crassa light serves as a major developmental stimulus. Aerial hyphae and conidiophores, destined to generate macroconidia, the multinucleate asexual spores, develop toward the light (Faull 1930). In addition, conidia develop more rapidly in mycelium exposed to light (Turian 1977), and their number is enhanced by light (F.-R. Lauter, unpubl.). Light stimulates sexual differentiation markedly as well; it increases production of the female fruiting structure, the protoperithecium (Degli-Innocenti et al. 1983).

As one approach to examining the regulatory events responsible for conidia formation, a group of conidiationspecific genes $(c o n)$ were cloned and characterized. The mRNAs transcribed from these con genes were shown to accumulate during conidiation (Berlin and Yanofsky 1985b). The nucleotide sequences of con-8 (Roberts and Yanofsky 1989), con-10 (Roberts et al. 1988), con-13 (Hager and Yanofsky 1990), con-6 (B. White and C. Yanofsky, in prep.), and con-11 (C. Yamashiro and C. Yanofsky, in prep.) have been determined, and their gene products have been partially characterized (Berlin and Yanofsky 1985b; Roberts et al. 1988; Roberts and Yanofsky 1989; Hager and Yanofsky 1990; Springer and Yanofsky 1992; Springer et al. 1992; B. White and C. Yanofsky; C. Yamashiro and C. Yanofsky; both in prep.). Each of these con genes has been inactivated, and there was no discernible effect on phenotype (Springer et al. 1992; C.

\footnotetext{
${ }^{2}$ Corresponding author.
}

Yamashiro; B. White; and C. Yanofsky; unpubl.). Two of the con genes, con-5 and con-10, were observed to be transcriptionally activated by blue light following growth as mycelium in the dark (Lauter and Russo 1991).

In an analogous approach in which the objective was identifying genes that were transcriptionally activated by light, four bli (blue light inducible) genes were sloned (Sommer et al. 1989). Transcripts of these genes were detectable in illuminated but not in dark-grown mycelia. The nucleotide sequence of one of the bli genes, bli-7, was determined and the amino acid sequence of its polypeptide product was deduced (Eberle and Russo 1992). The identity and specific function of the predicted polypeptide were unknown. Genetic data indicated that bli-7 (Pandit and Russo 1991) and the mutation easily wettable (eas) (Seltrennikoff 1976) mapped to the same region of the right arm of chromosome II, raising the possibility that bli-7 was eas.

In this paper we demonstrate that bli-7 is the gene eas and that it encodes the major rodlet protein of $N$. crassa. The rodlet layer of many fungal species, including $N$. crassa, is an aggregate containing the major surface protein of conidia and is presumed to provide a protective shell that renders asexual spores rigid and hydrophobic (Beever and Dempsey 1978). We also show that bli-7, like the con genes, is developmentally regulated during conidia formation and that its expression is influenced by mutations that block conidiation. The deduced polypeptide product of eas of $N$. crassa is homologous to the rodlet protein of Aspergillus nidulans and the hydrophobins of Schizophyllum commune. 


\section{Results}

\section{EAS (BLI7) homology to RodA}

The gene bli-7 of $N$. crassa was isolated previously by differential hybridization using a screening procedure designed to detect genes that are more highly expressed following exposure of dark-grown mycelia to blue light (Sommer et al. 1989). bli-7 cDNA and genomic DNA were sequenced, and the transcriptional startpoint was determined (Eberle and Russo 1992). Using restriction fragment length polymorphism techniques (Metzenberg et al. 1984) bli-7 was localized to the right arm of chromosome II, near the fluffy (fl) and eas loci (Pandit and Russo 1991). bli-7 consists of two exons and was predicted to encode a 108-residue polypeptide (Eberle and Russo 1992).

When we aligned the predicted amino acid sequences of BLI7 and RodA, the rodlet protein of A. nidulans (Stringer et al. 1991), on the basis of their prominent cysteine residues, we noticed considerable sequence similarity (Fig. 1A). BLI7 and RodA clearly share the same structural features. Both polypeptides are highly hydrophobic; BLI7 contains $40 \%$ and RodA contains $39 \%$ hydrophobic amino acid residues: A, F, I, L, M, and $\mathrm{V}$. The hydrophobic residues are mostly conserved within the two polypeptide chains (Fig. 1A); consequently, hydrophobicity plots are similar (Fig. 1B). Each of the polypeptides contains 8 (conserved) cysteine residues (Fig. 1A). These cysteine residues are not exclusively associated with particular predicted secondary structures. However, most are embedded in nonhydrophobic segments of the respective polypeptides (Fig. 1B). The Chou and Fasman (1978) algorithm was used to predict secondary structures within the polypeptide chains (Devereux et al. 1984). Both polypeptides have an aminoterminal secretion signal sequence; this is the only segment of these polypeptides that is predicted to form an $\alpha$-helix. BLI7 also has significant sequence similarity to three extracellular polypeptides from the basidiomycete S. commune (see Fig. 1A and Discussion; Schuren and Wessels 1990; Wessels et al. 1991; Eberle and Russo 1992).

The structural similarity of BLI7 and RodA suggests that these polypeptides have similar functions in $N$. crass $a$ and $A$. nidulans. Inactivation of the $\operatorname{rod} A$ gene of $A$. nidulans gives a mutant phenotype in which the cells of conidiophores and mature conidia lack the rodlet layer, making them less hydrophobic than in wild type (Stringer et al. 1991). This defect results in inefficient spore dispersal. The same phenotype was described for

B
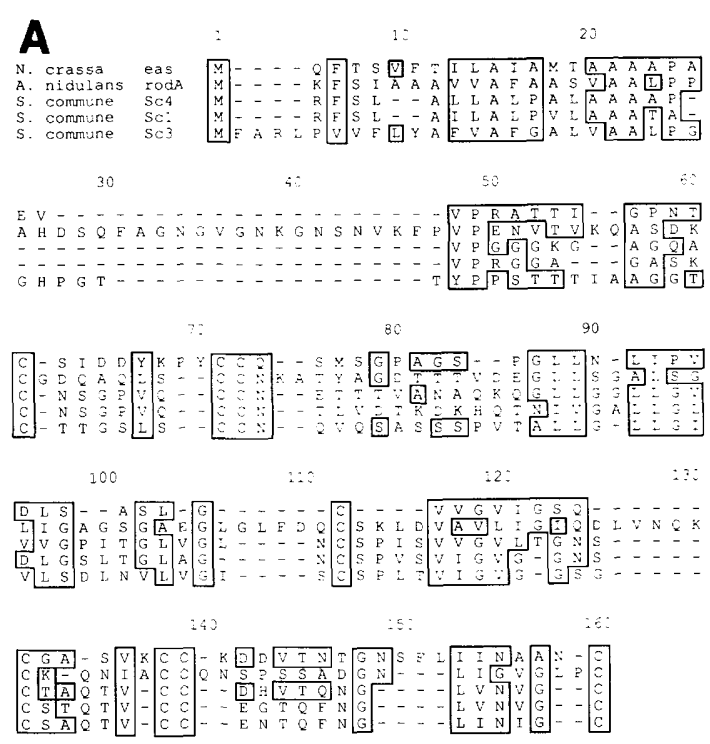
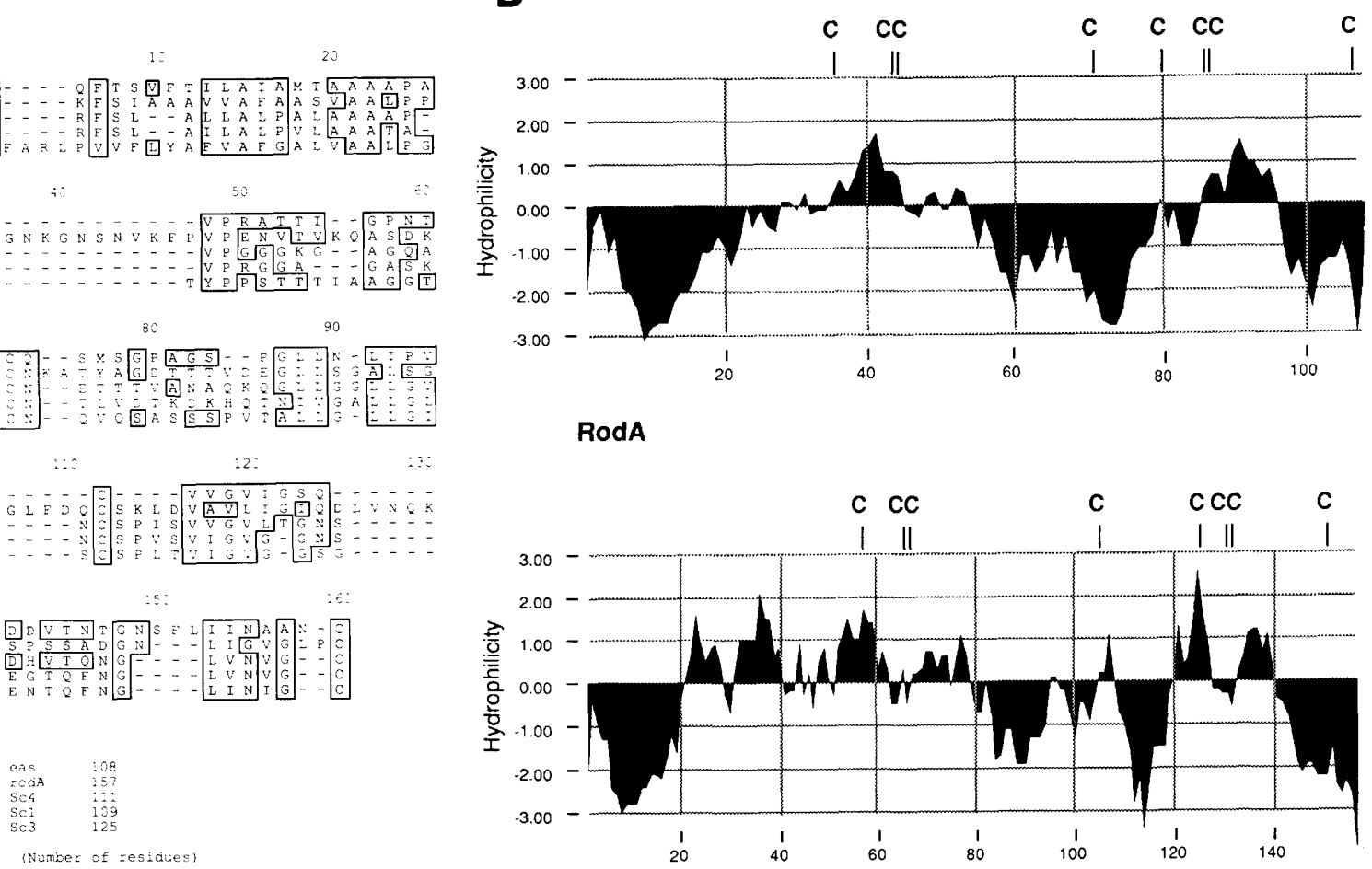

RodA

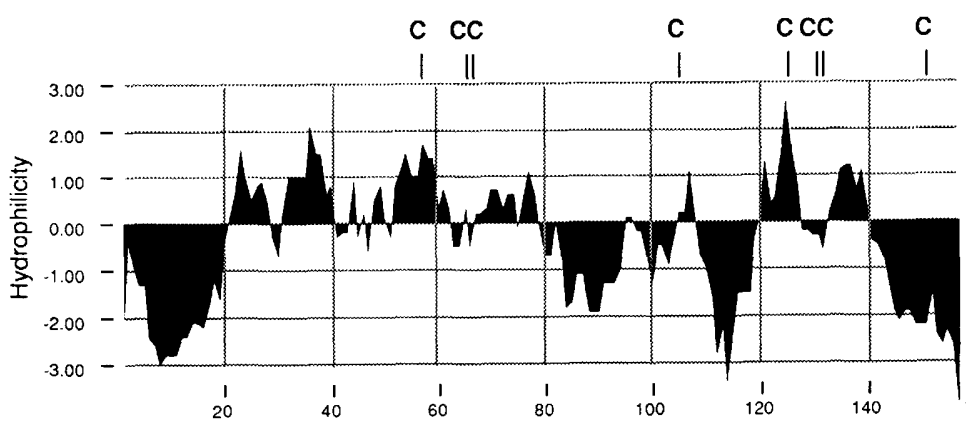

Figure 1. Comparison of the predicted polypeptides encoded by eas, $\operatorname{rodA}, S c 1, S c 3$, and $S c 4$. $|A|$ Predicted sequences were first aligned by their 8 cysteine residues, and their flanking and intervening residues were aligned by using the TULLA program of the University of Wisconsin GCG sequence analyses package (Devereux et al. 1984). Identities and conservative substitutions between EAS and the other polypeptides are boxed. RodA has $31 \%$, Scl has $29 \%$, Sc3 has $32 \%$ and Sc4 has $35 \%$ amino acid identities with EAS. $(B)$ Hydrophobicity plots of EAS and RodA generated using the IBI sequence analysis program Mac Vector, release 3.5. The Kyte-Doolittle algorithm was used with a window size of 7 . Hydrophilic segments are indicated above the $\mathrm{x}$-axis. The position of each cysteine residue is indicated by a $\mathrm{C}$ at the top of the hydrophobicity plot. 
the eas mutant strain UCLA191 of $N$. crassa (Selitrennikoff 1976; Beever and Dempsey 1978). In wild type, the product of eas, the rodlet protein, is secreted and deposited on the cell walls of conidia, where it forms insoluble rodlet complexes (Beever and Dempsey 1978; Dempsey et al. 1979).

The presence of rodlets on the surface of conidia can be scored macroscopically by either of two criteria. First, in a normal humid environment eas conidia appear wet and reddish-orange while wild-type conidia appear dry and yellowish-orange. Second, when agar slant cultures are tapped, wild-type conidia are dispersed while eas mutant conidia are not.

\section{Complementation of the eas mutation} in strain UCLA191

To determine whether bli-7 is eas we performed a complementation test with bli-7 DNA and the eas mutant strain UCLA191. [Henceforth, we refer to this strain /allele) as eas(191)]. A circular plasmid, pBLI7, consisting of $\sim 2.7 \mathrm{~kb}$ of pUC19 vector DNA and a 9.5-kb HindIII genomic DNA fragment containing the bli-7 gene (Eberle and Russo 1992) (Fig. 2A), was used in a transformation experiment with eas(191) (Selitrennikoff 1976) as a recipient. This plasmid was cotransformed with plasmid pMP6, selecting for hygromycin B resistance. Resistant colonies were isolated and screened for those displaying the wild-type phenotype, that is, hydrophobic conidia that are easily dispersed by air. Two transformants of this type, E006 and E007, were selected for analysis. Southern blot analysis of the DNA of these transformants (Fig. 2B) demonstrated that in E007, bli-7 DNA was incorporated by homologous integration generating a tandem duplication lan $\sim 20$-kb EcoRI fragment in wild-type was replaced by an $\sim 23-\mathrm{kb}$ fragment in eas(191)], whereas in E006, bli-7 DNA was incorporated ectopically (Fig. 2B). In E006 endogenous eas(191) DNA and heterologous integrated $e^{+}{ }^{+}$DNA were not present in equimolar amounts (Fig. 2B), indicating that this transformant was a heterokaryon. Two transformants that did not show eas complementation, E015 and E031, were found to lack bli-7 DNA (Fig. 2B).

On the basis of genetic studies with eas(191), David Perkins has proposed that the eas(191) mutation involved an insertion of a segment of cya-8 DNA into the eas locus (Selker 1990; D. Perkins and V. Pollard, pers. comm.). To examine this hypothesis and to confirm that bli-7 is eas, we compared restriction patterns of DNA isolated from wild-type 74-OR23-1VA and from mutant eas(191); these strains are isogenic (Selitrennikoff 1976). Results of Southern blot analyses probed with bli-7 DNA indicated that $\mathrm{a} \sim 2$-kb DNA insert was present between the EcoRI and NheI sites in the eas region of the eas(191) strain (Fig. 2A,B) [the $\sim 3.6-\mathrm{kb}$ EcoRI-Nhel fragment in wild-type was replaced by an $\sim 5.6$-kb fragment in eas(191)). Further studies localized the insert between 1.5 and $1.0 \mathrm{~kb}$ (DraI and HpaI site in Fig. 2A) upstream of the transcription startpoint. These findings establish that bli-7 is eas and that mutant eas(191) contains a
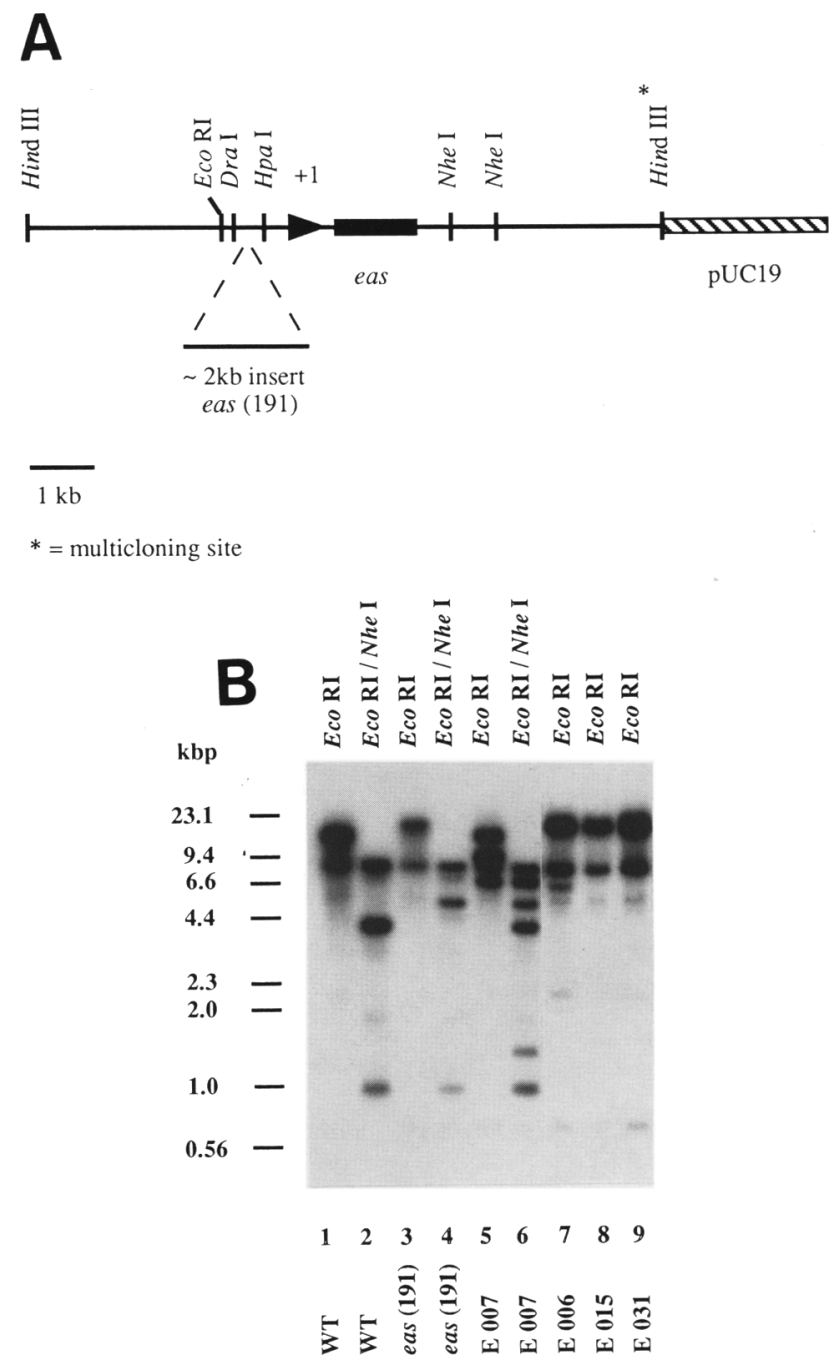

Figure 2. (A) Schematic of the bli-7 insert in pUC19. Also indicated is the site of insertion of an $\sim 2-\mathrm{kbp}$ fragment in eas(191). (B) Southern blot analysis of DNA from wild-type and various eas $^{+}$and eas $^{-}$transformants. Two transformants that showed eas complementation, E006 and E007, and two transformants that did not, E015 and E31, were analyzed. DNA was isolated from wild-type strain 74-OR23-1VA (WT), mutant eas(191), and transformants E006, E007, E015, and E031. Isolated DNA was digested with the EcoRI endonuclease or with both EcoRI and NheI endonucleases. Restricted DNA $13 \mu \mathrm{g} /$ lane) was separated by electrophoresis in a $1.0 \%$ agarose gel, transferred to a nylon membrane, and hybridized with the radiolabeled $N$. crassa HindIII DNA fragment shown in $A$. The sizes of the DNA standards used are given in $\mathrm{kbp}$ at left.

DNA insert that is probably located in the eas promoter. In other studies it was shown that mutational inactivation of bli-7 by the repeat induced point (RIP) mutation process (Selker 1990) resulted in progeny with the eas phenotype (F.-R. Lauter, unpubl.).

\section{Developmental and photoregulation of eas}

The conclusion that the eas locus encodes the rodlet 
protein of $N$. crassa prompted an analysis of developmental regulation of eas expression, using bli-7 (eas) DNA as a probe. The eas transcript was not detectable or was barely detectable in mature macroconidia, germinating macroconidia (Fig. 3), dark-grown mycelia (Fig. 4), and conidiating cultures (Fig. 3) during the first $4 \mathrm{hr}$ after induction of conidiation. eas mRNA was abundant 4-8 $\mathrm{hr}$ after induction of conidiation, and it remained elevated for an additional $20 \mathrm{hr}$ (Fig. 3). The low level of eas mRNA that was occasionally observed in macroconidia could be the result of contamination with aerial hyphae or conidiophores (see Material and methods). eas mRNA was not detected in RNA isolated from purified microconidia or ascospores (Fig. 3).

bli-7 mRNA accumulation is known to be under blue light control in vegetative mycelia (Sommer et al. 1989). After $60 \mathrm{~min}$ of continuous illumination the eas transcript appeared; it was abundant after $180 \mathrm{~min}$ of illumination (Fig. 4). As a control in these hybridization experiments, tub-2 mRNA levels were measured; $t u b-2$ encodes $N$. crassa $\beta$-tubulin (Orbach et al. 1986). Consistent with previous results, tub-2 mRNA levels were higher in germinating conidia than in mature conidia or in cultures induced to conidiate (Sachs and Yanofsky 1991).

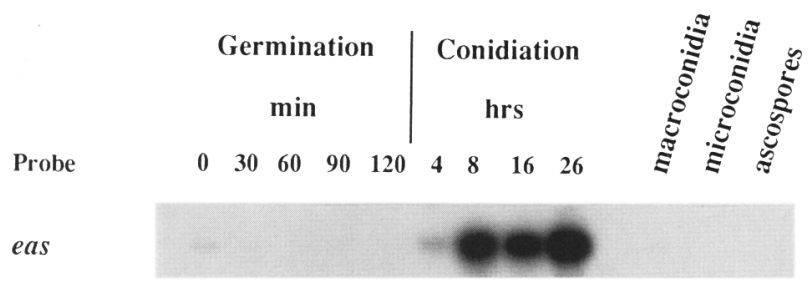

$t u b-2$

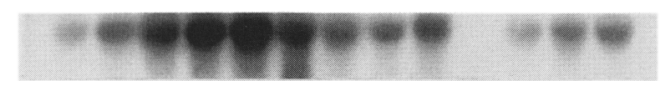

Figure 3. eas mRNA accumulation during $N$. crassa development. mRNA accumulation was measured in wild-type by Northern blot analysis. Total RNA was isolated from dormant macroconidia, microconidia, ascospores, and germinating macroconidia and conidiating cultures (see Material and methods). Macroconidia were inoculated in minimal medium and germinated for 30, 60, 90, and $120 \mathrm{~min}$ as indicated [Germination (min)]. RNA samples were also obtained from cultures that were harvested after $20 \mathrm{hr}$ of growth, induced to conidiate, and were sampled at 4, 8, 16, or $26 \mathrm{hr}$; [Conidiation (hrs)]. Total RNA samples $(10 \mu \mathrm{g} / \mathrm{lane})$ were fractionated by electrophoresis through formaldehyde-agarose gels ( $1.5 \%$ agarose) and transferred to a nylon membrane. Membranes were probed with ${ }^{32} \mathrm{P}$ labeled eas-specific antisense RNA. The same membranes were stripped and rehybridized with a tub-2 DNA probe. Probes are indicated at left. Specific transcripts were visualized by autoradiography. The germination- and conidiation-specific RNA samples were those used in previous studies (Sachs and Yanofsky 1991). The microconidia- and ascospore-specific RNA samples were those used in a previous study (Springer and Yanofsky 1992). Microconidia were obtained from a $f l_{\text {; }} d n$ double mutant strain, and ascospores were obtained from $f 1$, a X 74-OR23-1VA cross.

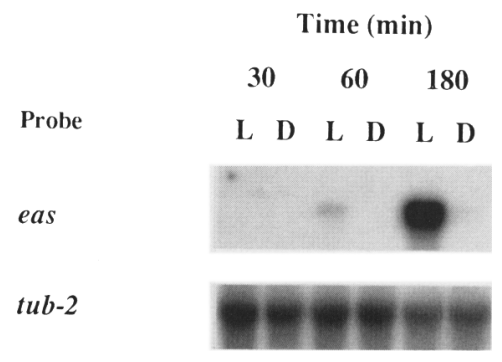

Figure 4. Photo-induced accumulation of eas mRNA in vegetative mycelia. Accumulation was measured in N. crassa wild type by Northern blot analysis, using ${ }^{32}$ P-labeled antisense easspecific RNA as a probe. RNA was isolated from 30-, 60-, and 180-min illuminated mycelia (L). Mycelia were kept in the dark for identical periods of time as controls (D). Equal amounts of total RNA $(10 \mu \mathrm{g})$ were loaded in each lane and analyzed as described in the legend to Fig. 3. Membranes were rehybridized with a radiolabeled tub-2 DNA probe. Additional RNA samples isolated from a second series of cultures were analyzed in parallel, with similar results (data not shown).

\section{Accumulation of eas mRNA in morphological mutants}

Several morphological mutants are known that are blocked at different stages of conidial development. The morphology of these mutants has been characterized by scanning electron microscopy (Springer and Yanofsky 1989). In the temperature-sensitive mutant aconidiate-2 (acon-2) grown at the nonpermissive temperature $34^{\circ} \mathrm{C}$, conidiation is blocked before the minor constriction stage, that is, aerial hyphae production proceeds, but the hyphae never bud. Two other mutants, aconidiate-3 (acon-3) and fl (Matsuyama et al. 1974), are blocked subsequently, before what has been called the major constriction stage (Springer and Yanofsky 1989). Mutants conidial-separation-1 (csp-1), and conidial-separation-2 (csp-2) proceed through the early stages of conidiation, but their conidia fail to separate (Selitrennikoff et al. 1974). In eas(191), conidiation proceeds normally, but conidia lack their hydrophobic outer layer.

eas transcript levels were measured in growing mycelial cultures of these different morphological mutants and in cultures subjected to environmental conditions that induce conidiation (see Material and methods; Berlin and Yanofsky 1985a). eas mRNA was not detectable or was barely detectable in vegetative mycelia of any of the mutants tested (Fig. 5). However, under conidiationinducing conditions that are effective for wild-type, the eas transcript level was comparable to wild-type in acon2 , at both the permissive and nonpermissive temperatures, and in acon-3, csp-1, and csp-2 (Fig. 5 |. eas mRNA levels were greatly reduced in $f 1$ and eas(191), (Fig. 5). Under conidiation-inducing conditions we estimate that in mutant eas(191), the eas mRNA level is only a few percent that of wild-type (see Fig. 5). The eas transcript size was unaltered in eas (191). This finding suggests that the DNA insertion in eas partially inactivated its promoter. However, eas(191) was still developmentally regulated. 


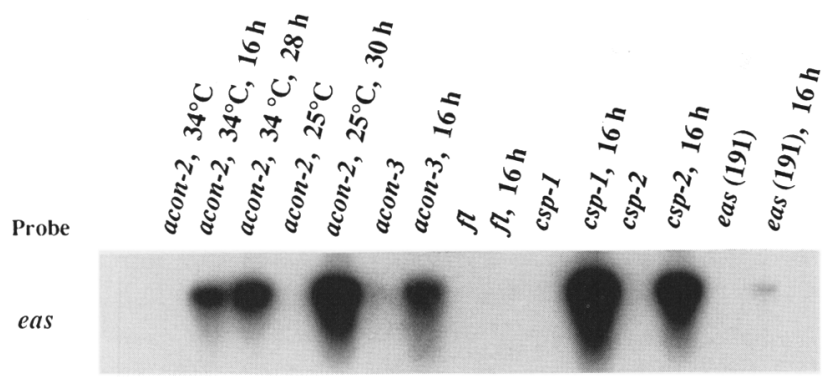

$t u b-2$

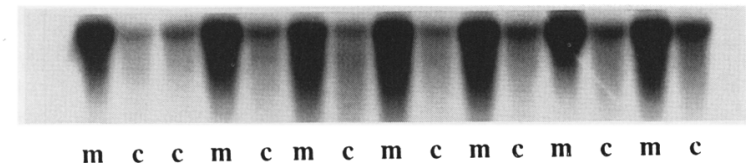

Figure 5. eas mRNA accumulation in developmental mutant strains of $N$. crassa. Accumulation was measured in acon-2, acon-3, fl, csp-1, csp-2, and eas(191) mutant strains by Northern blot analysis, using radiolabeled eas-specific antisense RNA as a probe. Total RNA was isolated from vegetatively growing mycelia $(\mathrm{m})$ and cultures induced to conidiate $(\mathrm{c})$. After $20 \mathrm{hr}$ of growth in liquid minimal medium, mycelia were harvested by filtration and either used as a source of mycelial RNA $(\mathrm{m})$ or induced to conidiate. With the exception of acon-2, total RNA was prepared from the different mutant strains after $16 \mathrm{hr}$ of incubation $(16 \mathrm{~h})$ under conidiating conditions $(\mathrm{c})$. After induction, acon-2 was incubated at the permissive temperature $\left(25^{\circ} \mathrm{C}\right)$ for $30 \mathrm{hr}$ and at the nonpermissive temperature $\left(34^{\circ} \mathrm{C}\right)$ for 16 and $28 \mathrm{hr}$. Equal amounts of total RNA $(10 \mu \mathrm{g})$ were loaded in each lane and analyzed as described in the legend to Fig. 3. Membranes were rehybridized with a radiolabeled tub-2 DNA probe. The RNA samples were those used in previous studies (Roberts et al. 1988; Roberts and Yanofsky 1989).

tub-2 mRNA was measured as a control and was more abundant in vegetative mycelia than under conidiationinducing conditions for all the mutants tested (Fig. 5).

\section{Discussion}

In this report we have demonstrated that bli-7 and eas are identical and that eas encodes the rodlet protein of $N$. crassa. Thus, eas is the first cloned conidiation gene of
$N$. crassa that is associated with a phenotypic alteration and is shown to be a member of the hydrophobin gene family. The level of eas-specific mRNA was shown to be regulated both developmentally and by light. Normal developmental regulation of eas required a functional $f l$ gene product.

\section{Properties of the eas protein product}

The product of eas, the rodlet protein of $N$. crassa, is known to be secreted and deposited on the cell walls of conidia, where it forms insoluble rodlet complexes (Beever and Dempsey 1978; Dempsey et al. 1979) (Fig. 6). The gene encoding the rodlet protein of $A$. nidulans, $\operatorname{rod} A$, has been isolated, and the sequence of its polypeptide, RodA, has been deduced (Stringer et al. 1991). RodA and EAS share a number of structural features. Both are hydrophobic polypeptides, both contain 8 cysteine residues, and both have an amino-terminal secretion signal sequence. Rodlet complexes may be dependent on disulfide cross-links and hydrophobic interactions between subunits. Three cell wall proteins, hydrophobins, of the basidiomycete $S$. commune, Sc1, Sc3, and Sc4 (Wessels et al. 1991), show the same structural features. Sc3 encodes a hydrophobin present in the wall of aerial hyphae, whereas the homologous $S c 1$ and $S c 4$ are present in the wall of the hyphae of the fruiting body. Hydrophobins are believed to be instrumental in the appearance of these aerial structures (Wessels et al. 1991). It has been suggested in studies with $N$. crassa that emergence of surface hyphae through the water-air interface is facilitated by the deposition of hydrophobic molecules on the hyphal surface (Weiss and Turian 1966). Thus, EAS, RodA, Sc1, Sc3, and Sc4 appear to be members of a class of hydrophobic outer wall proteins whose function is to provide a hydrophobic shell. It has been proposed that these proteins contribute to other fungal aerial structures as well (Stringer et al. 1991; for review, see Chasan 1991). The view that more than one hydrophobin/rodletlike protein may be present in each fungal species is supported by the discovery of three different hydrophobins in Schizophyllum (Wessels et al. 1991).

The rodlet layer on $N$. crassa conidia is readily removed by suspending conidia in water and shaking

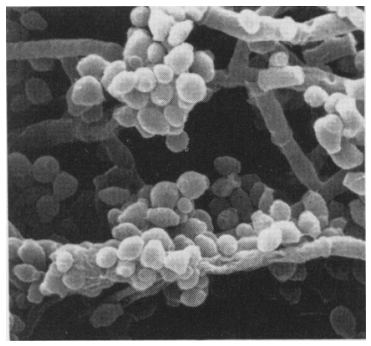

A

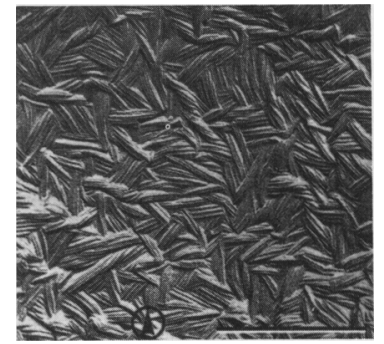

B

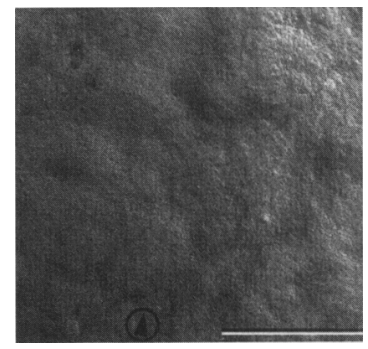

C
Figure 6. Electron microscopy of wildtype and eas conidia. (A) Mature macroconidia of wild-type examined by scanning electron microscopy. The average diameter of a macroconidium is $\sim 5 \mu \mathrm{m}$. This micrograph was taken by Matthew Springer using a described procedure (Springer and Yanofsky 1989). (B,C) Electron micrographs of the surface of conidia of wildtype and eas(191). The direction of carbon/ platinum shadowing is indicated by an encircled arrowhead (bottom). Bars represent $0.5 \mu \mathrm{m}$. Micrographs $B$ and $C$ were published earlier (reprinted, with permission, from Beever and Dempsey 1978). 
(Dempsey and Beever 1979). It has been reported that neither the rodlet protein of $A$. nidulans (Stringer et al. 1991) nor the hydrophobins of $S$. commune (Wessels et al. 1991) will assemble at the outer cell wall if developmental structures are allowed to form in submerged cultures. Furthermore, A. nidulans conidia produced in submerged cultures lack the rodlet layer, even though $\operatorname{rod} A$ mRNA accumulates under these conditions (Adams et al. 1988). Similarly, when $S$. commune is grown on the underside of netting that is floating on liquid, the submerged hyphae do not incorporate hydrophobins into their walls (Wessels et al. 1991); nevertheless, $S c$ transcripts accumulate (Mulder and Wessels 1986). In $N$. crassa, eas mRNA is abundant in conidiating cultures that are grown submerged. It has been estimated that eas mRNA constitutes $0.2 \%$ of the total RNA mass in submerged growing cultures that have been induced to conidiate (Sokolvsky et al. 1992). This level would correspond to $\sim 10-20 \%$ of the total poly $(\mathrm{A})^{+}$mRNA (Sachs and Yanofsky 1991). It is possible that submerged $N$. crassa cultures do not accumulate rodlet protein on their outer cell walls because rodlet complexes are washed away by the medium.

\section{Light and developmental regulation of eas mRNA production}

In vegetative mycelia grown in total darkness $(24 \mathrm{hr}$ after germination), the eas transcript level was low. Upon illumination of mycelia, eas mRNA became abundant. It was shown previously that the products of the white collar genes (wc-1 and $w c-2$ ) were required for photoinduced accumulation of eas mRNA (bli-7 mRNA) (Sommer et al. 1989). It is conceivable that light serves as the signal to the growing fungus that its hyphae have reached a water-air interface and that it should switch to the aerial growth mode. Interestingly, in S. commune, transcription of $S c 1, S c 3$, and $S c 4$ also is under light control (Yli-Mattila et al. 1989). The relevance of this light effect has not been explored. Light is essential for conidiation in A. nidulans (Mooney and Yager 1990) but not in Neurospora. The effect of light on rodA mRNA accumulation has not been reported.

A time line of conidiophore development in $N$. crassa has been proposed on the basis of studies employing scanning electron microscopy (Springer and Yanofsky 1989). About $1-2 \mathrm{hr}$ after induction of conidiation, aerial hyphae form and cover the mycelial surface. Conidiation begins when some of these aerial hyphae branch and the branches change their growth mode from hyphal tip elongation to repeated apical budding, generating what has been termed minor constriction chains. Budding begins $\sim 2 \mathrm{hr}$ after induction. At $4 \mathrm{hr}$ after induction, these chains form most of the aerial mass. As chains continue to bud, the interconidial junctions become more pronounced and form what has been termed major constrictions. From this stage on, additional growth proceeds by continued formation of major constriction chains which, by $8 \mathrm{hr}$ following induction, constitute almost the entire population of proconidial chains (Springer and Yanofsky
1989|. The eas transcript becomes abundant during the transition from minor to major constriction budding. Presumably during this period, EAS protein is synthesized in large amounts and transported to the surface of developing conidia where it is deposited on the outer cell wall. Rodlet proteins account for $\sim 2 \%$ of the conidial dry weight (Beever et al. 1979). There is substantial evidence that light is not essential for formation and deposition of the rodlet protein on the surface of conidia in $N$. crassa. Conidia that are produced by $w c-1$ or $w c-2 \mathrm{mu}-$ tant strains or by wild-type grown in darkness are as hydrophobic as wild-type conidia that have developed in the light (results not shown).

\section{eas $m R N A$ in developmental mutants}

The gene products of $a c o n-2$, acon-3, and $f 1$ are needed for early conidiophore development. acon-2 is necessary for the formation of minor constrictions during proconidial budding, whereas acon- 3 and $f l$ are necessary at the next step in the process of budding-formation of major constrictions (Springer and Yanofsky 1989). Proper transcriptional regulation of eas requires the $f l$ gene product but not either the $a c 0 n-2$ or acon-3 product. A second conidiation gene, con- 6 , has an expression pattern resembling eas; transcription is blocked in $f l$ but not in acon-2 and acon-3 (Roberts and Yanofsky 1989). Proper transcription of the conidiation genes con-10, con-11, and con-13 requires the products of all three genes, acon-2, acon-3, and $f 1$ (Roberts and Yanofsky 1989|. The finding that eas transcription is blocked by $f 1$ but not by acon-2 is consistent with the appearance of abundant eas mRNA during the transition from minor to major constriction budding. In addition, aerial hyphae of fl mutant strains are easily wettable (D. Perkins, pers. comm.) and therefore probably lack EAS, whereas those of wild-type, acon-2, and acon-3 are not and probably contain rodlet protein (F.-R. Lauter, unpubl.).

In the eas(191) mutant an insertion of $\sim 1.0-1.5 \mathrm{~kb}$ upstream of the eas transcription startpoint (DraI-HpaI fragment in Fig. 2A) greatly reduced eas mRNA accumulation during conidiation. Deletion of this DraI-HpaI fragment resulted in the elimination of eas transcription (R. Kaldenhoff and V. Russo, unpubl.). These results suggest that important regulatory elements that affect eas transcription are located between 1.0 and $1.5 \mathrm{~kb}$ upstream of its transcriptional startpoint.

\section{General transcriptional features}

The findings described in this paper establish that either blue light illumination or asexual spore development can activate transcription of eas, the gene encoding the major coat protein of the conidium. It has also been shown that con genes isolated on the basis of preferential expression during conidiation may be transcriptionally activated by light (Lauter and Russo 1991); thus, it is apparent that genes showing a transcriptional response to different stimuli may participate in the same process. Several con genes are also transcriptionally activated 
along developmental pathways, leading to the formation of the other two types of spores, microconidia and ascospores (Springer and Yanofsky 1992).

We have compared the sequence of the eas clone with that of other clones containing $N$. crassa genes in an effort to identify possible cis-acting elements. Two sequence similarities were found. First, as reported elsewhere (Eberle and Russo 1992), grg-1 of N. crassa, encoding a glucose-repressible gene (McNally and Free 1988), and eas share $\sim 70 \%$ of the 150 bp surrounding their transcriptional startpoints. Second, a DNA element believed to participate in developmental regulation of con-6 and con-10 (B. White and C. Yanofsky; D. Ebbole and C. Yanofsky; both in prep.) was present in the eas upstream region. Analyzing the regulatory factors and sites responsible for light and developmental control is the next challenge.

\section{Material and methods}

Strains and plasmids

The wild-type strain of $N$. crassa used was 74-OR23-1VA (FGSC 987). The mutants examined include acon-2, acon- $3, f 1, c s p-1$, csp-2, and eas(191) (for details, see Roberts et al. 1988). All strains are described in Perkins et al. (1982). To obtain microconidia, the $f 1 ; d n$ double mutant strain was used (Wilson 1985). Subclones for transformation and radiolabeling were constructed in the vectors pUC19 and pGEM4Z (Promega). Plasmids pBLI7 (Eberle and Russo 1992) and pMP6 were used for eas(191) transformation. pBLI7 contains a 9.5-kb HindIII fragment of $N$. crassa genomic DNA cloned into pUC19. In pMP6, a modified promoter of the $c p c-1$ gene (Paluh et al. 1988) is fused to the bacterial hygromycin phosphotransferase gene, conferring hygromycin B resistance on the fungus (Staben et al. 1989). The 730-bp eas (bli-7) cDNA fragment (Sommer et al. 1989) was cloned into the EcoRI site of the vector pGEM4Z. This plasmid was used to generate eas antisense RNA. The plasmid pBT3 was used as a source of tub-2-specific DNA (Orbach et al. 1986).

\section{Isolation of nucleic acids}

Plasmid DNA was isolated by the alkaline lysis method (Birnboim and Doly 1979). Large-scale plasmid preparations were banded in cesium chloride-ethidium bromide gradients. $N$. crassa RNA was prepared as described by Berlin and Yanofsky (1985b) or according to the protocol of Sachs and Yanofsky (1991), with the exception that cells were disrupted using a mini-bead beater. Genomic DNA was purified from mycelia of $N$. crassa grown for $20 \mathrm{hr}$ at $34^{\circ} \mathrm{C}$ with agitation in $75 \mathrm{ml}$ of Vogel's minimal medium (Davis and de Serres 1970). Mycelia were lyophilized, mechanically pulverized, RNase treated, and extracted with phenol-chloroform as described by Lee et al. (1988).

\section{Preparation of DNA/RNA probes}

Radiolabeled $t u b-2$ DNA probes were prepared by hexamer priming (Feinberg and Vogelstein 1983). Radiolabeled eas RNA probes were prepared by generating ${ }^{32} \mathrm{P}$-labeled antisense eas RNA (Zinn et al. 1983).

\section{Filter blot hydridizations}

Northern analyses using DNA probes were carried out as described (Berlin and Yanofsky 1985b). Northern analyses using
RNA probes were carried out following the protocol of Zinn et al. (1983). Southern analyses were performed according to Southern (1975).

\section{Transformation and growth of N. crassa}

Transformation Germination, spheroplasting, and transformation of eas(191) conidia were performed as described (Vollmer and Yanofsky 1986), using $3 \mu \mathrm{g}$ of CsCl-purified pBLI7 and $1 \mu \mathrm{g}$ of $\mathrm{CsCl}$-purified pMP6 per transformation. The selective medium used was Vogel's minimal salts containing sorbose as a carbon source and $250 \mu \mathrm{g} / \mathrm{ml}$ of hygromycin B.

Germination Frozen conidia of the wild-type strain 74OR23-1VA were harvested in water, filtered through sterile cheesecloth to remove hyphae and conidiophore fragments, and inoculated at $2 \times 10^{7}$ conidia $/ \mathrm{ml}$ in $400 \mathrm{ml}$ of Vogel's minimal salts with $1.5 \%$ sucrose as carbon source in a 2-liter baffled flask shaken at $200 \mathrm{rpm}$. Twenty-five-milliliter $\left(5 \times 10^{8}\right.$ conidia and germlings) samples were taken after growth for 30,60, 90, and $120 \mathrm{~min}$ at $34^{\circ} \mathrm{C}$. Samples were cooled rapidly (but not frozen) in dry ice/ethanol to stop germination and pelleted for $10 \mathrm{~min}$ at 2000g. Pellets were used for extraction of RNA (Sachs and Yanofsky 1991).

Conidiation Growth conditions and media are described in Berlin and Yanofsky (1985a). Mycelial cultures were grown in liquid medium under uncontrolled lighting for $\sim 20 \mathrm{hr}$. Conidiation was induced by filtration onto Whatman No. 1 paper discs. Discs were placed on a monolayer of glass beads in petri dishes containing Vogel's minimal medium and incubated in a sterile hood under fluorescent light (Berlin and Yanofsky 1985a). Conidial samples were harvested 4, 8, 16, 26, or $30 \mathrm{hr}$ after induction of conidiation. Samples were frozen in liquid nitrogen, and RNA was extracted.

Microconidia, macroconidia, and ascospores Macroconidia were isolated by filtration through cheesecloth as described above. Microconidia were isolated by harvesting in water from a 250-ml Erlenmeyer flask culture of $f 1$; $d n$ grown on $50 \mathrm{ml}$ of agar-solidified Vogel's minimal medium. Ascospores from a 74OR23-1VA $\times f 1$ cross were collected from the lid of a crossing plate. Routine crosses and manipulations were performed as described by Davis and de Serres (1970) and Perkins (1986). RNA was prepared from those different spores according to the protocol of Sachs and Yanofsky (1991).

Light induction $N$. crassa mycelia were grown in the dark in $75 \mathrm{ml}$ of liquid medium in 250-ml flasks to the late logarithmical phase and were harvested by filtration in the dark as described (Chambers et al. 1985). Harvested mycelial pads were cut in half; one-half was photoinduced with white light, and the other half served as a dark control. Illumination with white light (Chambers et al. 1985) was for 30,60, or $180 \mathrm{~min}$. Mycelia illuminated for those periods of time were immediately frozen in liquid nitrogen. The fluency rate of the blue part of the white light was $6 \mathrm{~W} / \mathrm{m}^{2}$.

\section{Acknowledgments}

We are grateful to David Perkins for his encouragement, support, and for sharing results before publication. We thank Anne Roberts, Matthew Springer, and Brian White for providing RNA samples. We thank Ross Beever, Ajith Kamath, Dorothy Newmeyer, Niketan Pandit, David Perkins, John Royer, Matthew Springer, and Carl Yamashiro for their critical comments on the manuscript and Jürgen Eberle and Brian White for sharing unpublished results. We are grateful to Ross Beever, Ian Hallett, and Matthew Springer for kindly providing electron micro- 
graphs. F.R.L. was supported by a fellowship of the Deutsche Forschungsgemeinschaft (La 714/1-1). C.Y. is a Career Investigator of the American Heart Association. This work was supported by grant AM41296 from the National Institutes of Health (to C.Y.).

The publication costs of this article were defrayed in part by payment of page charges. This article must therefore be hereby marked "advertisement" in accordance with 18 USC section 1734 solely to indicate this fact.

\section{Note}

As we were about to submit this manuscript on eas we learned from Dr. Jay Dunlap that he was preparing a manuscript describing findings with the same gene, which his group has cloned and named ccg-2 (see Bell-Pedersen et al., this issue; Loros et al. 1989|.

\section{References}

Adams, T.H., M.T. Boylan, and W.E. Timberlake. 1988. brlA is necessary and sufficient to direct conidiophore development in Aspergillus nidulans. Cell 54: 353-362.

Beever, R.E. and G.P. Dempsey. 1978. Function of rodlets on the surface of fungal spores. Nature 272: 608-610.

Beever, R.E., R.J. Redgwell, and G.P. Dempsey 1979. Purification and chemical characterization of the rodlet layer of Neurospora crassa conidia. J. Bacteriol. 140: 1063-1070.

Berlin, V. and C. Yanofsky. 1985a. Protein changes during the asexual cycle of Neurospora crassa. Mol. Cell. Biol. 5: 839848.

- 1985b. Isolation and characterization of genes differentially expressed during conidiation of Neurospora crassa. Mol. Cell. Biol. 5: 849-855.

Birnboim, H.C. and J. Doly. 1979. A rapid alkaline extraction procedure for screening recombinant plasmid DNA. Nucleic Acids Res. 7: 1513-1523.

Chambers, J.A.A., K. Hinkelammert, and V.E.A. Russo. 1985. Light-regulated protein and poly $(A)^{+}$mRNA synthesis in Neurospora crassa. EMBO \%. 4: 3649-3653.

Chasan, R. 1991. Building hyphae in the air. The Plant Cell 3: $1048-1050$.

Chou, P.Y. and G.D. Fasman. 1978. Prediction of the secondary structure of proteins from their amino acid sequence. $A d v$. Enzymol. 47: 45-148.

Davis, R.H. and F.J. de Serres. 1970. Genetic and microbial research techniques for Neurospora crassa. Methods Enzymol. 17A: 47-143.

Degli-Innocenti, F., U. Pohl, and V.E.A. Russo. 1983. Photoinduction of protoperithecia in Neurospora crassa by blue light. Photochem. Photobiol. 37: 49-51.

Dempsey, G.P. and R.E. Beever. 1979. Electron microscopy of the rodlet layer of Neurospora crassa conidia. I. Bacteriol. 140: 1050-1062.

Dempsey, G.P., R.J. Redgwell, and R.E. Beever, 1979. Purification and chemical characterization of the rodlet layer of Neurospora crassa conidia. I. Bacteriol. 140: 1063-1070.

Devereux, J., P. Haeberli, and O. Smithies. 1984. A comprehensive set of sequence analysis programs for the VAX. Nucleic Acids Res. 12: 387-395.

Eberle, J. and V.E.A. Russo. 1992. Neurospora crassa blue-lightinducible gene bli-7 encodes a short hydrophobic protein. DNA sequence (in press).

Faull, A.F. 1930. On the resistance of Neurospora crassa. Mycologia 22: 288-303.

Feinberg, A.P. and B. Vogelstein. 1983. A technique for radiola- beling DNA restriction fragments to high specific activity. Anal. Biochem. 132: 6-13.

Hager, K.M. and C. Yanofsky. 1990. Genes expressed during conidiation in Neurospora crassa: Molecular characterization of con-13. Gene 96: 153-159.

Lauter, F.-R. and V.E.A. Russo. 1991. Blue light induction of conidiation-specific genes in Neurospora crassa. Nucleic Acids Res. 19: 6883-6996.

Lee, S.B., M.G. Milgroom, and J.W. Taylor. 1988. A rapid, high yield miniprep method for isolation of total genomic DNA from fungi. Fungal Genet. Newsl. 35: 23-24.

Loros, J.J., S.A. Denome, and J.C. Dunlap 1989. Molecular cloning of genes under control of the circadian clock in Neurospora. Science 243: 385-388.

Matsuyama, S.S., R.E. Nelson, and R.W. Siegel. 1974. Mutations specifically blocking differentiation of macroconidia in $\mathrm{Neu}$ rospora crassa. Dev. Biol. 41: 278-287.

McNally, M.T. and S.F. Free. 1988. Isolation and characterization of a Neurospora glucose-repressible gene. Curr. Genet. 14: 545-551.

Metzenberg, R.L., J.N. Stevens, E.U. Selker, and E. MorzyckaWroblewska. 1984. A method for finding the genetic map position of cloned DNA fragments. Neurospora Newls. 31: 35-39.

Mooney, J.L. and L.N. Yager. 1990. Light is required for conidiation in Aspergillus nidulans. Genes \& Dev. 4: 1473-1482.

Mulder, G.H. and J.G.H. Wessels. 1986. Molecular cloning of RNAs differentially expressed in monokaryons and dikaryons of Schizophyllum commune in relation to fruiting. Exp. Mycol. 10: 214-227.

Orbach, M.J., E.B. Porro, and C. Yanofsky. 1986. Cloning and characterization of the gene for $\beta$-tubulin from a benomylresistant mutant of Neurospora crassa and its use as a dominant selectable marker. Mol. Cell. Biol. 6: 2452-2461.

Paluh, J.L., M.J. Orbach, T.L. Legerton, and C. Yanofsky. 1988. The cross-pathway control gene of Neurospora crassa, cpc-1, encodes a protein similar to GCN4 of yeast and the DNA binding domain of the oncogene v-jun-encoded protein. Proc. Natl. Acad. Sci. 85: 3728-3732.

Pandit, N.N. and V.E.A. Russo. 1991. The bli regulon-A network of blue light inducible genes of Neurospora crassa. Fungal Gene. Newsl. 38: 93-95.

Perkins, D.D. 1986. Hints and precautions for the care, feeding and breeding of Neurospora. Fungal Genet. Newsl. 33: 3441.

Perkins, D.D., A. Radford, D. Newmeyer, and M. Bj̄rkman. 1982. Chromosomal loci of Neurospora crassa. Microbiol. Rev. 46: 426-570.

Roberts, A.N. and C. Yanofsky. 1989. Genes expressed during conidiation in Neurospora crassa: Characterization of con-8. Nucleic Acids Res. 17: 197-213.

Roberts, A.N., V. Berlin, K.M. Hager, and C. Yanofsky. 1988. Molecular analysis of a Neurospora crassa gene expressed during conidiation. Mol. Cell. Biol. 8: 2411-2418.

Sachs, M.S. and C. Yanofsky. 1991. Developmental expression of genes involved in conidiation and amino acid biosynthesis in Neurospora crassa. Dev. Biol. 148: 117-128.

Schuren, F.H.J. and J.G.H. Wessels. 1990. Two genes specifically expressed in fruiting dikaryons of Schizophyllum commune: Homologies with a gene not regulated by mating-type genes. Gene 90: 199-205.

Selitrennikoff, C.P. 1976. Easily-wettable, a new mutant. Neurospora Newsl. 23: 23.

Selitrennikoff, C.P., R.E. Nelson, and R.W. Siegel. 1974. Phasespecific genes for macroconidiation in Neurospora crassa. Genetics 78: 679-690. 
Selker, E.U. 1990. Premeiotic instability of repeated sequences in Neurospora crassa. Annu. Rev. Genet. 24: 579-613.

Sokolovsky, V.Y., F.-R. Lauter, B. Müller-Röber, M. Ricci, T.J. Schmidhauser, and V.E.A. Russo. 1992. Nitrogen regulation of blue light-inducible genes in Neurospora crassa. I. Gen. Microbiol. 138: (in press).

Sommer, T., J.A.A. Chambers, J. Eberle, F.-R. Lauter, and V.E.A. Russo. 1989. Fast light-regulated genes of Neurospora crassa. Nucleic Acids Res. 17: 5713-5723.

Southern, E.M. 1975. Detection of specific sequences amoung DNA fragments separated by gel electrophoresis. I. Mol. Biol. 98: 503-517.

Springer, M.L. and C. Yanofsky. 1989. A morphological and genetic analysis of conidiophore development in Neurospora crassa. Genes \& Dev. 3: 559-571.

- 1992. Expression of con genes along the three sporulation pathways of Neurospora crassa. Genes \& Dev. 6: 10521057.

Springer, M.L., K.M. Hager, C. Garrett-Engele, and C. Yanofsky. 1992. Timing of synthesis and cellular localization of two conidiation-specific proteins of Neurospora crassa. Dev. Biol. 152: 255-262.

Staben, C., B. Jensen, M. Singer, J. Pollock, M. Schechtman, J. Kinsey, and E. Selker. 1989. Use of a bacterial Hygromycin B resistance gene as a dominant selectable marker in Neuros. pora crassa transformation. Fungal Genet. Newsl. 36: 7081.

Stringer, M.A., R.A. Dean, T.C. Sewall, and W.E. Timberlake. 1991. Rodletless, a new Aspergillus developmental mutant induced by directed gene inactivation. Genes \& Dev. 5: 1161-1171.

Turian, G. 1977. Fungal differentiation. In Biotechnology and fungal differentiation (ed. J. Meyrath, and J.D. Bu'Lock) pp. 1-15, Academic Press, London, England.

Vollmer, S.J. and C. Yanofsky. 1986. Efficient cloning of genes of Neurospora crassa. Proc. Natl. Acad. Sci. 83: 4869-4873.

Weiss, B. and G. Turian. 1966. A study of conidiation in Neurospora crassa. J. Gen. Microbiol. 44: 407-418.

Wessels, J.G.H., O.M.H. de Vries, S.A. Asgeirsdottir, and F.H.J. Schuren. 1991. Hydrophobin genes involved in formation of aerial hyphae and fruit bodies in Schizophyllum. The Plant Cell 3: 793-799.

Wilson. C.H. 1985. Production of microconidia by several $f 1$ strains. Neurospora Newsl. 32: 18.

Yli-Mattila, T., M.H.J. Ruiters, and J.G.H. Wessels. 1989. Photoregulation of dikaryon-specific mRNAs and proteins by UV-A light in Schizophyllum commune. Curr. Microbiol. 18: 289-295.

Zinn, K., D. DiMaio, and T. Maniatis. 1983. Identification of two distinct regulatory regions adjacent to the human interferon gene. Cell 34: 865-879. 


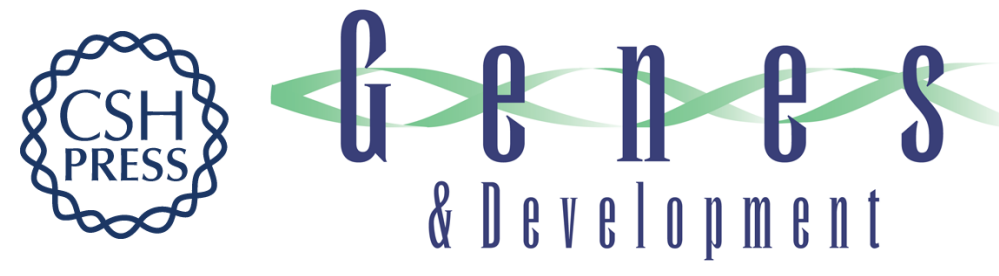

\section{Developmental and light regulation of eas, the structural gene for the rodlet protein of Neurospora.}

F R Lauter, V E Russo and C Yanofsky

Genes Dev. 1992, 6:

Access the most recent version at doi:10.1101/gad.6.12a.2373

References This article cites 50 articles, 17 of which can be accessed free at:

http://genesdev.cshlp.org/content/6/12a/2373.full.html\#ref-list-1

License

Email Alerting

Service

Receive free email alerts when new articles cite this article - sign up in the box at the top right corner of the article or click here.

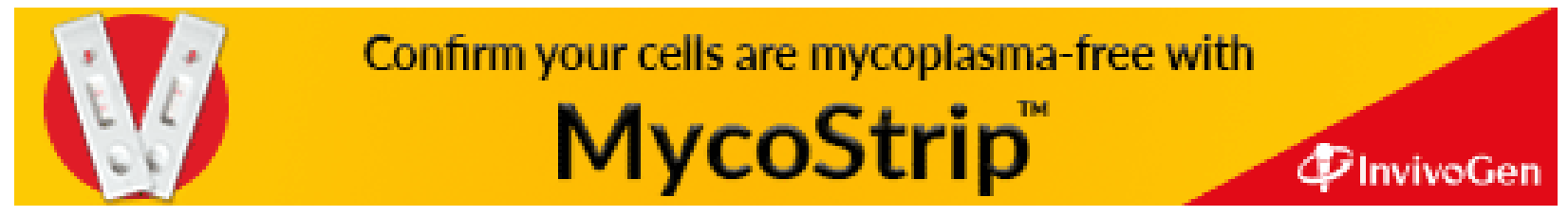

